\title{
Effect of adhesive mode and chlorhexidine on microtensile strength of universal bonding agent to sound and caries-affected dentins
}

\author{
Joyce Figueiredo Macedo de Lima ${ }^{1}$, Danielle Wajngarten ${ }^{2}$, Fariya Islam ${ }^{3}$, \\ Johanna Clifford $^{3}$, Ana Carolina Botta ${ }^{3}$
}

Correspondence: Dr. Ana Carolina Botta

Email: anacarolina.deoliveira@stonybrookmedicine.edu
'Department of Restorative Dentistry, Piracicaba School of Dentistry, Unicamp, Piracicaba, Sao Paulo, Brazil,

${ }^{2}$ Department of Social Dentistry, Araraquara Dental School, Sao Paulo State University (UNESP), Araraquara, Sao Paulo, Brazil,

${ }^{3}$ Department of General Dentistry, Stony Brook University, School of Dental Medicine, NY, USA

\section{ABSTRACT}

Objective: The main objective of this study is to assess the effect of the adhesive mode and chlorhexidine (CHX) on the microtensile strength of a universal bonding agent to sound and caries-affected dentins. Materials and Methods: Six intact third molars and six decayed third molars were sectioned to obtain two middle dentin specimens per tooth. Prime and Bond Elect Universal (Dentsply) was applied to specimens in two different modes: Etch-and-rinse (ER, phosphoric acid for 15s) and self-etch (SE, no phosphoric acid). 2\% CHX (Cavity Cleanser, Bisco) was applied to both dentins for $30 \mathrm{~s}$. Specimens were randomly assigned into eight groups $(n=3)$ according to the treatments applied to sound and caries-affected dentins: SE; ER; SE + CHX; and ER + CHX. All specimens were restored with TPH Spectra High Viscosity (Dentsply) composite resin and sectioned to obtain specimens of $0.8 \pm 0.1 \mathrm{~mm}^{2}$. The microtensile bond strength test was conducted at $1 \mathrm{~mm} / \mathrm{min}$. The data were statistically analyzed by ANOVA and multiple comparisons' test $(\alpha=0.05)$. Results: There was no significant difference between sound dentin and caries-affected dentin $(P=0.132)$. The highest bond strength was obtained with the application of the ER $(31.81 \mathrm{MPa})$. SE + CHX promoted the lowest bond strength with no statistical difference to ER + CHX $(P>0.05)$. Conclusions: ER mode for the universal bonding agent yielded the highest bond strength to sound and caries-affected dentins. CHX reduced the bond strength to both dentins regardless the application of phosphoric acid. Clinical Significance: The universal bonding agent increased the bond strength to sound and caries-affected dentins when applied by the ER mode.

Key words: Acid etching, chlorhexidine, dentin, dentin adhesives, tensile strength

\section{INTRODUCTION}

One of the highest challenges in adhesive dentistry is to find a versatile bonding agent that promotes adequate bond strength to both enamel and dentin, ${ }^{[1]}$ low technique sensitivity, ${ }^{[1,2]}$ and high

\begin{tabular}{|l|l|}
\hline \multicolumn{3}{|c|}{ Access this article online } \\
\hline Quick Response Code: \\
\hline
\end{tabular}

longevity. ${ }^{[3-5]}$ Although universal bonding agents have been introduced to clinical dentistry recently,

This is an open access journal, and articles are distributed under the terms of the Creative Commons Attribution-NonCommercial-ShareAlike 4.0 License, which allows others to remix, tweak, and build upon the work non-commercially, as long as appropriate credit is given and the new creations are licensed under the identical terms.

For reprints contact: reprints@medknow.com

How to cite this article: Macedo de Lima JF, Wajngarten D, Islam F, Clifford J, Botta AC. Effect of adhesive mode and chlorhexidine on microtensile strength of universal bonding agent to sound and cariesaffected dentins. Eur J Dent 2018;12:553-8.

DOI: 10.4103/ejd.ejd_239_18 
satisfactory results have been observed for both enamel and dentin due to their composition and multimode techniques (etch-and-rinse [ER]; self-etch [SE]; and selective etch). ${ }^{[1]}$

It is already known that ER mode is the chosen technique to bond enamel, due to complete removal of the smear layer and demineralization of enamel rods by phosphoric acid and penetration of resin monomers in the demineralized area, resulting in chemical-mechanical retention and consequently high bond strength to enamel. ${ }^{[1,4,5]}$ However, the most appropriate adhesive mode to dentin is still controversial due to the complex morphology and physicochemical characteristics of sound and caries-affected dentin. ${ }^{[6]}$ The dentin bond strength is affected by the degradation of collagen that occurs in the dentin-resin interface. ${ }^{[7]}$ This is partly due to the activity of matrix metalloproteinases (MMPs), ${ }^{[8-11]}$ a class of endogenous enzymes of proteolytic action of collagen, which can become active by contact even with weak acids. ${ }^{[10,12-14]}$

To prevent the loss of bond strength to dentin by hydrolysis and to maintain the integrity of the restoration in long-term, some strategies have been studied for inhibiting the MMPs. ${ }^{[15]}$ They include the incorporation of agents such as polymerizable quaternary ammonium methacrylates and benzalkonium chloride in self-etching primers, ${ }^{[16,17]}$ the use of calcium and zinc with ethylene diamine tetraphosphoric acid as a conditioner, ${ }^{[18-20]}$ the production of synthetic MMP inhibitors as the chemically modified tetracyclines, ${ }^{[21]}$ and the use of chlorhexidine (CHX) as an antimicrobial agent. ${ }^{[22]}$

$\mathrm{CHX}$ has demonstrated the most outstanding results for reducing the residual risk of infection and increasing the bond strength to dentin by inhibition of activated MMP enzymes. ${ }^{[22]}$ This outcome depends on CHX concentration ${ }^{[15,22]}$ and type of substrate (sound or caries-affected dentin) used. ${ }^{[23]}$ Although CHX has increased the bond strength to dentin, its effect on different dentin substrates when applied previously to universal bonding agents on SE and ER modes has not been completely studied.

Therefore, the aim of this study was to assess the effect of the adhesive mode (SE or ER) and CHX on the microtensile strength of one-step universal bonding agent to sound and caries-affected dentins. The null hypotheses tested were: (1) the factor "type of dentin" has no significant effect on bond strength; (2) the factor "type of treatment used" has no significant effect on bond strength; and (3) the interaction between the factors "dentin" $\times$ "treatment" has no significant effect on the bond strength.

\section{MATERIALS AND METHODS}

\section{Specimens preparation}

This study was reviewed and approved by the Ethics Committee for Human Studies (CORIHS\#: 2016-3766-F), Stony Brook University, NY, USA. Six intact third molars and six decayed third molars were cleaned and stored in $0.5 \%$ chloramine solution (Fisher Scientific, Pittsburg, PA, USA) at $4^{\circ} \mathrm{C}$ for 7 days. ${ }^{[24]}$ After the disinfection process, all teeth were sectioned $2.5 \mathrm{~mm}$ above and $4.0 \mathrm{~mm}$ below the cementum-enamel junction with a precision low-speed diamond saw (ISOMET 1000, Buehler, Illinois, USA). A buccolingual section perpendicular to the others was done to obtain two dentin specimens per tooth [Figure 1]. An explorer and a stereoscopic microscope at $\times 10$ magnification (Zeiss West Germany-type 475200/9901) were used to detect sound and caries-affected dentins. Affected dentin was described as a dentin exposed to bacterial acids but is not yet infected by cariogenic bacteria. ${ }^{[25]}$ Caries-affected dentin was diagnosed as discolored or stained ${ }^{[25]}$ by visual inspection with the stereoscopic microscope and leathery and softer than sound dentin by tactile inspection with an explorer. Coronary and radicular pulp was removed with hand instruments at the root apex. The root canals were etched with $34 \%$ phosphoric acid (Dentsply, Milford, DE, USA) for $15 \mathrm{~s}$ and sealed with a

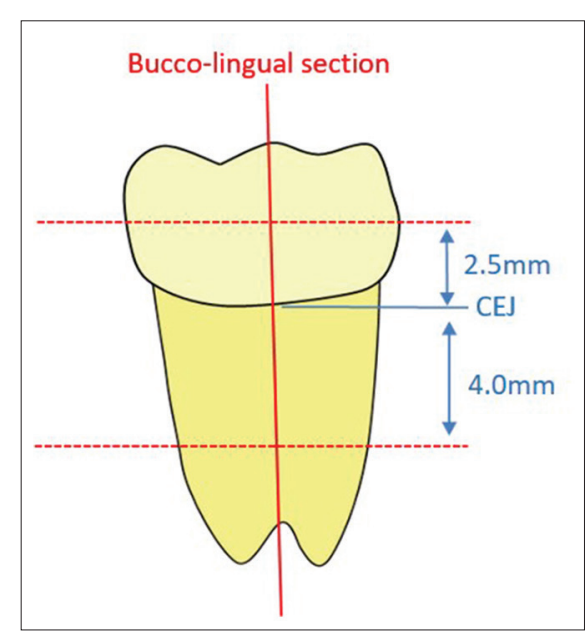

Figure 1: Specimens preparation. Third molars were sectioned $2.5 \mathrm{~mm}$ above and $4 \mathrm{~mm}$ below the cementum-enamel junction. A buccolingual section perpendicular to the others was done to obtain two dentin specimens per tooth 
universal bonding agent (Prime and Bond Elect, Dentsply) and a flowable composite (TPH Flow, Dentsply) following the manufacturers' instructions.

\section{Restorative procedures}

To standardize the smear layer, sandpaper silicon carbide with grain 600 was used on the dentin for 1 min. ${ }^{[26]}$

Specimens were randomly assigned into eight experimental groups according to the adhesive mode (SE or ER) and application of 2\% CHX (Cavity Cleanser, Bisco Inc., Schaumburg, IL, USA) to sound and caries-affected dentins: SE; ER; SE + CHX; and $\mathrm{ER}+\mathrm{CHX}$.

Prime and Bond Elect was applied to dentin specimens following the manufacturers' instructions and two different adhesive modes: (1) ER: Application of $34 \%$ phosphoric acid for $15 \mathrm{~s}$ and (2) SE: No application of $34 \%$ phosphoric acid. 2\% CHX was applied for $30 \mathrm{~s}^{[27]}$ with a microbrush on dentin specimens after the acid etching in the ER mode and before the universal bonding agent in the SE mode.

After the surface treatment of the substrates, $5 \mathrm{~mm}$ restorations were built following the incremental technique with a universal resin composite (TPHSpectra High viscosity, A2 shade, Dentsply). Each $2 \mathrm{~mm}$ increment was light cured for $20 \mathrm{~s}$ (SmartLite Focus light curing unit, $1000 \mathrm{mw} / \mathrm{cm}^{2}$, Dentsply) following the manufacturer' recommendations.

All restored specimens were stored in distilled water at $37^{\circ} \mathrm{C}$ for $24 \mathrm{~h}$ and then assigned to microtensile bond strength test.

\section{Microtensile bond strength test}

Specimens were sectioned with a precision low-speed diamond saw to obtain sticks with a cross-sectional area of $0.8 \pm 0.1 \mathrm{~mm}^{2}$. An absolute digital caliper (Mitutoyo Corp., Kanagawa, Japan) with an accuracy of $0.001 \mathrm{~mm}$ was used to measure both sides of the adhesive interface. The bonding area was calculated in $\mathrm{mm}^{2}$ automatically by the Instron software. Each stick was tested individually by attaching them to a microtensile jig using a cyanoacrylate glue (Zapit Accelerator Dental Ventures of America Inc., Corona, CA, USA). All sticks were then subjected to a microtensile load $(100 \mathrm{~N})$ using a universal testing machine (Instron Co., Canton, MA, USA) at $1 \mathrm{~mm} / \mathrm{min}$ crosshead speed. The load (N) and the bonding surface area were registered and the microtensile bond strength calculated in $\mathrm{MPa}$ by the BlueHill program software. Failures were evaluated using the Zeiss stereoscopic microscope at $\times 10$ magnification and classified as adhesive, cohesive, mixed, or debonded.

\section{RESULTS}

The interaction between the factors "dentin" $\times$ "treatment" had no significant effect on the bond strength $(P=0.475)$. In addition, there was no statistically significant difference between sound and caries-affected dentin, regardless of the adhesive mode and CHX application $(P=0.132)$. The type of treatment affected the bond strength regardless of the type of dentins $(P<0.001)$ [Table 1 ].

The highest bond strength was obtained with the ER mode (31.81 MPa). SE + CHX had the lowest bond strength with no statistical difference for $\mathrm{ER}+\mathrm{CHX}(P>0.05)$.

Figures 2 and 3 present the percentage of failures according to the type of treatment applied to sound and caries-affected dentins, respectively.

The adhesive failure was predominant for all treatments on sound and caries-affected dentins, except for SE + CHX.

\section{Table 1: Homogeneous groups, median, and quartiles (quartile 1; quartile 3 ) in MPa according to the type of treatment applied to both sound and caries-affected dentins

\begin{tabular}{lcc}
\hline Treatments & Median (quartiles) & Homogenous groups* \\
\hline SE & $16.01(0.01 ; 29.99)$ & $\mathrm{B}$ \\
ER & $31.81(22.36 ; 49.23)$ & $\mathrm{A}$ \\
$\mathrm{SE}+\mathrm{CHX}$ & $0.00(0.00 ; 25.82)$ & $\mathrm{C}$ \\
ER + CHX & $17.28(0.00 ; 24.71)$ & $\mathrm{BC}$ \\
\hline
\end{tabular}

Dunn test (5\%). Dentin: $F=0.512, P=0.475$, Treatment: $F=22.054, P<0.001$, *Multiple comparisons' post hoc: letters indicate statistical similarity, Dentin $\times$ treatment: $F=1.883, P=0.132$. SE: Self-etch, ER: Etch-and-rinse, CHX: Chlorhexidine

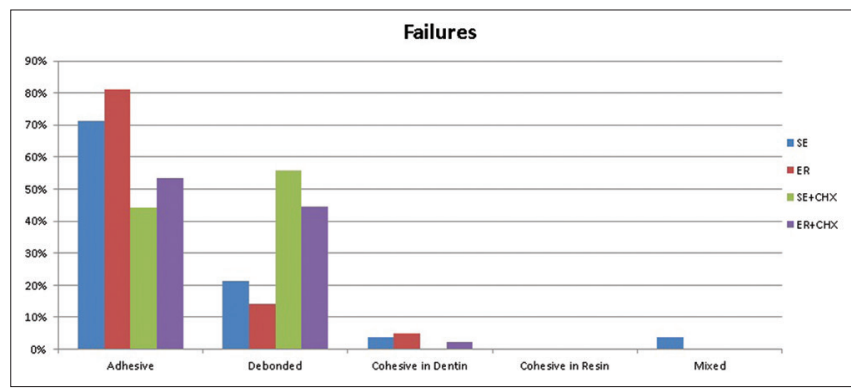

Figure 2: Frequency of failures according to the treatment applied to sound dentin 


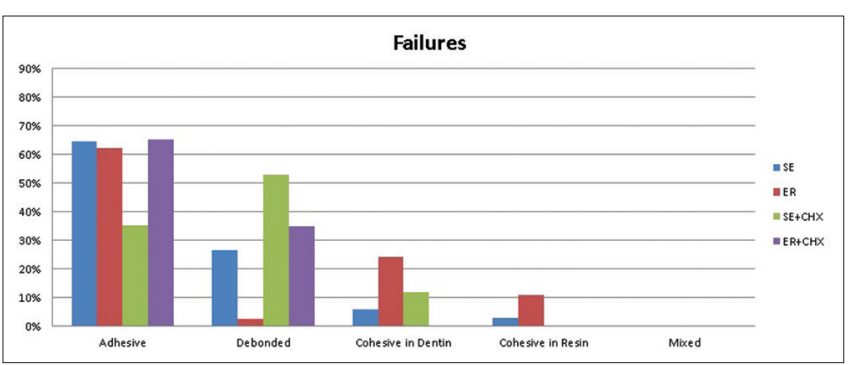

Figure 3: Frequency of failures according to the treatment applied to caries-affected dentin

\section{DISCUSSION}

The effect of adhesives modes and CHX on bond strength to sound and caries-affected dentin was evaluated in this study. Sound dentin is a complex substrate composed by hydroxyapatite $(50 \%)$, collagen $(30 \%)$, and water $(20 \%)$, and it is exposed to structural changes by physiological ${ }^{[28]}$ and pathological processes. ${ }^{[29]}$ Although studies ${ }^{[30]}$ have reported that caries-affected dentin exhibits increased collagenolytic activity when compared to sound dentin, which suggests faster bonding deterioration, ${ }^{[23]}$ no statistical difference was observed between both dentin regardless the adhesive mode and $\mathrm{CHX}$ application. Therefore, the first and third null hypotheses of this study were accepted. Similar finding was observed by Tosun et al. ${ }^{[31]}$ through the scanning electron microscopy. Although caries-affected dentin is more porous and softer than sound dentin, no morphological difference was observed in the thickness of the hybrid layer between sound and caries-affected dentin, which explains the reason the bond strength was not affected by the dentin substrate. ${ }^{[31]}$

The second null hypothesis was rejected because the bond strength was modified by the type of treatment: Adhesive mode and CHX application. Although studies have shown that the bond strength of universal adhesive systems to dentin was not affected when the phosphoric acid was used before the application of adhesives, ${ }^{[29,32]}$ in the present study, the ER mode increased significantly the bond strength of the universal bonding agent, regardless dentin substrate. Rosa et al. ${ }^{[29]}$ suggested that the differences in the compositions of the universal adhesives systems may be the reason for the different performances of phosphoric acid on bond strength. Our results are also in accordance to Muñoz et al. ${ }^{[33]}$ and Tekçe et al. ${ }^{[34]}$ who found lower values of bond strength to dentin in the SE mode for different universal adhesive systems used when compared to ER mode. This can be explained by the characteristics of the acidic primer contained in the Prime and Bond Elect, which can be classified as ultra-weak according to its $\mathrm{pH}$ and depth of penetration to dentin $(\mathrm{pH}>2.5$, depth $0.2-0.5 \mu \mathrm{m}$ penetration). As the smear layer and the dissolved calcium phosphates ${ }^{[1]}$ are only partially removed by the ultra-weak acidic monomers, they become a physical barrier for the formation of the hybrid layer. ${ }^{[35,36]}$

In contrast, $30 \%-40 \%$ phosphoric acid exposes collagen fibers through the dentin demineralization with simultaneous removal of the smear layer and the dissolved calcium phosphate. ${ }^{[2,30]}$ In addition, other studies have shown that the use of phosphoric acid before the SE adhesive system ${ }^{[34,35]}$ and the universal adhesive system (ER mode) ${ }^{[32]}$ has provided a deeper penetration of resin monomers, generating longer tags, and thicker hybrid layers.

It is known that MMPs are present in the exposed and noninfiltrated collagen beneath in the hybrid layer and can be activated by the presence of weak acids in both ER or SE systems. ${ }^{[36-38]}$ High bond strength to dentin is obtained when the bonding agent is able to infiltrate the exposed collagen by acid or inhibit the MMPs located in the demineralized area. ${ }^{[39]} \mathrm{CHX}$ works as a therapeutic primer and a nonspecific inhibitor modifying the three-dimensional structure of the MMPs and competing with metal ions $\left(\mathrm{Ca}^{2+}, \mathrm{Zn}^{2-}\right)$ necessary for their functions. ${ }^{[12,40]}$ Although there is evidence that $\mathrm{CHX}$ is capable of inhibiting the action of the MMPs, it is not clear its effect on the bond strength of universal adhesive systems because the results have been contradictory. ${ }^{[34]}$

In this study, the application of CHX resulted in a significant reduction of the bond strength to dentin for both adhesive modes (ER, SE) $24 \mathrm{~h}$ after the restorative procedure. Similar results were reported by Campos et al. ${ }^{[41]}$ and Gunaydin et al. ${ }^{[42]}$ The low bond strength can be explained by the formation of precipitates on the dentin surface after the application of $2 \%$ CHX as observed by Di Hipólito et al. ${ }^{[43]}$ through the scanning electron microscopy. The two positive charges of the symmetric CHX molecule ${ }^{[44]}$ can be electrostatically attracted to the phosphate anions present in the hydroxyapatite ${ }^{[45]}$ forming crystals in the form of "birefringent needles." ${ }^{[43]} 2 \%$ CHX affects the bond strength to dentin by decreasing the amount of calcium ions available on the dentin for chemical bonding to the adhesive system and also by forming crystals that act as a mechanical barrier to adequate hybrid layer formation. ${ }^{[43]}$ 
Although the application of CHX has affected the bond strength for both ER and SE modes, adhesive failures were predominant for the ER mode (53\% for sound dentin and $65 \%$ for caries-affected dentin) and debonded for the SE mode (56\% for sound dentin and $53 \%$ for caries-affected dentin). The phosphoric acid can have promoted a greater demineralization and removal of the smear layer on dentin surface and facilitated the penetration of the universal adhesive system, even with the presence of precipitates by the application of $\mathrm{CHX}$. As for the SE mode, the shallow penetration of the universal adhesive system associated with the effects of $\mathrm{CHX}$ on the dentin surface may have resulted in the formation of an inadequate hybrid layer, which would explain the higher number of premature failures in the adhesive interface.

Considering that this study assessed the effect of the adhesive mode and the CHX on the bond strength to dentin $24 \mathrm{~h}$ after a restorative procedure, other studies are needed to determine the effect of these treatments on bond strength to dentin in long-term and evaluate the morphology of the hybrid layer through microscopy analysis.

\section{CONCLUSIONS}

It was concluded that the ER mode for the universal bonding agent yielded the highest bond strength to sound and caries-affected dentins. CHX reduced the bond strength to both dentins regardless the adhesive mode.

\section{Financial support and sponsorship}

This study was financially supported by Brazil Scientific Mobility Program sponsored by CAPES and $\mathrm{CNPq}\left(\mathrm{n}^{\circ}\right.$ 15405996).

\section{Conflicts of interest}

There are no conflicts of interest.

\section{REFERENCES}

1. Van Meerbeek B, Yoshihara K, Yoshida Y, Mine A, De Munck J, Van Landuyt KL, et al. State of the art of self-etch adhesives. Dent Mater 2011;27:17-28.

2. Pashley DH, Tay FR, Breschi L, Tjäderhane L, Carvalho RM, Carrilho M, et al. State of the art etch-and-rinse adhesives. Dent Mater 2011;27:1-6.

3. De Munck J, Van Meerbeek B, Yoshida Y, Inoue S, Vargas M, Suzuki K, et al. Four-year water degradation of total-etch adhesives bonded to dentin. J Dent Res 2003;82:136-40.

4. Hashimoto M, Ohno H, Sano H, Kaga M, Oguchi H. In vitro degradation of resin-dentin bonds analyzed by microtensile bond test, scanning and transmission electron microscopy. Biomaterials 2003;24:3795-803.
5. Armstrong SR, Vargas MA, Chung I, Pashley DH, Campbell JA, Laffoon JE, et al. Resin-dentin interfacial ultrastructure and microtensile dentin bond strength after five-year water storage. Oper Dent 2004;29:705-12.

6. Perdigão J. Dentin bonding as a function of dentin structure. Dent Clin North Am 2002;46:277-301, vi.

7. Mjör IA, Moorhead JE, Dahl JE. Reasons for replacement of restorations in permanent teeth in general dental practice. Int Dent J 2000;50:361-6.

8. Mjör IA, Dahl JE, Moorhead JE. Age of restorations at replacement in permanent teeth in general dental practice. Acta Odontol Scand 2000;58:97-101

9. Pashley DH, Tay FR, Yiu C, Hashimoto M, Breschi L, Carvalho RM, et al. Collagen degradation by host-derived enzymes during aging. J Dent Res 2004;83:216-21.

10. Hebling J, Pashley DH, Tjäderhane L, Tay FR. Chlorhexidine arrests subclinical degradation of dentin hybrid layers in vivo. J Dent Res 2005;84:741-6.

11. Breschi L, Mazzoni A, Nato F, Carrilho M, Visintini E, Tjäderhane L, et al. Chlorhexidine stabilizes the adhesive interface: A 2-year in vitro study. Dent Mater 2010;26:320-5.

12. Osorio R, Yamauti M, Osorio E, Ruiz-Requena ME, Pashley D, Tay F, et al. Effect of dentin etching and chlorhexidine application on metalloproteinase-mediated collagen degradation. Eur J Oral Sci 2011;119:79-85.

13. Davis GE. Identification of an abundant latent $94-k$ Da gelatin-degrading metalloprotease in human saliva which is activated by acid exposure: Implications for a role in digestion of collagenous proteins. Arch Biochem Biophys 1991;286:551-4.

14. Gunja-Smith Z, Woessner JF Jr. Activation of cartilage stromelysin-1 at acid $\mathrm{pH}$ and its relation to enzyme $\mathrm{pH}$ optimum and osteoarthritis. Agents Actions 1993;40:228-31.

15. Zhou J, Tan J, Chen L, Li D, Tan Y. The incorporation of chlorhexidine in a two-step self-etching adhesive preserves dentin bond in vitro. J Dent 2009;37:807-12.

16. Imazato S, Kinomoto Y, Tarumi H, Ebisu S, Tay FR. Antibacterial activity and bonding characteristics of an adhesive resin containing antibacterial monomer MDPB. Dent Mater 2003;19:313-9.

17. Imazato S, Tay FR, Kaneshiro AV, Takahashi Y, Ebisu S. An in vivo evaluation of bonding ability of comprehensive antibacterial adhesive system incorporating MDPB. Dent Mater 2007;23:170-6.

18. Osorio R, Erhardt MC, Pimenta LA, Osorio E, Toledano M. EDTA treatment improves resin-dentin bonds' resistance to degradation. J Dent Res 2005;84:736-40.

19. Sauro S, Mannocci F, Toledano M, Osorio R, Pashley DH, Watson TF, et al. EDTA or $\mathrm{H} 3 \mathrm{PO} 4 / \mathrm{NaOCl}$ dentine treatments may increase hybrid layers' resistance to degradation: A microtensile bond strength and confocal-micropermeability study. J Dent 2009;37:279-88.

20. Imbery TA, Kennedy M, Janus C, Moon PC. Evaluating EDTA as a substitute for phosphoric acid-etching of enamel and dentin. Gen Dent 2012;60:e55-61.

21. Sorsa T, Tjäderhane L, Konttinen YT, Lauhio A, Salo T, Lee HM, et al. Matrix metalloproteinases: Contribution to pathogenesis, diagnosis and treatment of periodontal inflammation. Ann Med 2006;38:306-21.

22. Tjäderhane L, Nascimento FD, Breschi L, Mazzoni A, Tersariol IL, Geraldeli S, et al. Strategies to prevent hydrolytic degradation of the hybrid layer-A review. Dent Mater 2013;29:999-1011.

23. Mobarak EH. Effect of chlorhexidine pretreatment on bond strength durability of caries-affected dentin over 2-year aging in artificial saliva and under simulated intrapulpal pressure. Oper Dent 2011;36:649-60.

24. Sezinando A, Luque-Martinez I, Muñoz MA, Reis A, Loguercio AD, Perdigão $\mathrm{J}$, et al. Influence of a hydrophobic resin coating on the immediate and 6-month dentin bonding of three universal adhesives. Dent Mater 2015;31:e236-46.

25. Young DA, Nový BB, Zeller GG, Hale R, Hart TC, Truelove EL, et al. The American Dental Association Caries Classification System for clinical practice: A report of the American Dental Association Council on scientific affairs. J Am Dent Assoc 2015;146:79-86.

26. Pashley DH, Tao L, Boyd L, King GE, Horner JA. Scanning electron microscopy of the substructure of smear layers in human dentine. Arch Oral Biol 1988;33:265-70.

27. Leitune VC, Portella FF, Bohn PV, Collares FM, Samuel SM. Influence of chlorhexidine application on longitudinal adhesive bond strength in deciduous teeth. Braz Oral Res 2011;25:388-92.

28. Bertassoni LE, Habelitz S, Kinney JH, Marshall SJ, Marshall GW Jr. 
Biomechanical perspective on the remineralization of dentin. Caries Res 2009;43:70-7.

29. Rosa WL, Piva E, Silva AF. Bond strength of universal adhesives: A systematic review and meta-analysis. J Dent 2015;43:765-76.

30. Perdigão J. Dentin bonding-variables related to the clinical situation and the substrate treatment. Dent Mater 2010;26:e24-37.

31. Tosun G, Koyuturk AE, Sener Y, Sengun A. Bond strength of two total-etching bonding systems on caries-affected and sound primary teeth dentin. Int J Paediatr Dent 2008;18:62-9.

32. Wagner A, Wendler M, Petschelt A, Belli R, Lohbauer U. Bonding performance of universal adhesives in different etching modes. J Dent 2014;42:800-7.

33. Muñoz MA, Luque I, Hass V, Reis A, Loguercio AD, Bombarda NH, et al. Immediate bonding properties of universal adhesives to dentine. J Dent 2013;41:404-11.

34. Tekçe N, Tuncer S, Demirci M, Balci S. Do matrix metalloproteinase inhibitors improve the bond durability of universal dental adhesives? Scanning 2016;38:535-44.

35. Tani C, Finger WJ. Effect of smear layer thickness on bond strength mediated by three all-in-one self-etching priming adhesives. J Adhes Dent 2002;4:283-9.

36. De Munck J, Van Landuyt K, Peumans M, Poitevin A, Lambrechts P, Braem $\mathrm{M}$, et al. A critical review of the durability of adhesion to tooth tissue: Methods and results. J Dent Res 2005;84:118-32.

37. Nishitani Y, Yoshiyama M, Wadgaonkar B, Breschi L, Mannello F, Mazzoni A, et al. Activation of gelatinolytic/collagenolytic activity in dentin by self-etching adhesives. Eur J Oral Sci 2006;114:160-6.

38. Tay FR, Pashley DH, Loushine RJ, Weller RN, Monticelli F, Osorio R, et al. Self-etching adhesives increase collagenolytic activity in radicular dentin. J Endod 2006;32:862-8.

39. Liu Y, Tjäderhane L, Breschi L, Mazzoni A, Li N, Mao J, et al. Limitations in bonding to dentin and experimental strategies to prevent bond degradation. J Dent Res 2011;90:953-68.

40. Boushell LW, Swift EJ Jr. Critical appraisal. Dentin bonding: Matrix metalloproteinases and chlorhexidine. J Esthet Restor Dent 2011;23:347-52.

41. Campos EA, Correr GM, Leonardi DP, Pizzatto E, Morais EC. Influence of chlorhexidine concentration on microtensile bond strength of contemporary adhesive systems. Braz Oral Res 2009;23:340-5.

42. Gunaydin Z, Yazici AR, Cehreli ZC. In vivo and in vitro effects of chlorhexidine pretreatment on immediate and aged dentin bond strengths. Oper Dent 2016;41:258-67.

43. Di Hipólito V, Rodrigues FP, Piveta FB, Azevedo Lda C, Bruschi Alonso RC, Silikas N, et al. Effectiveness of self-adhesive luting cements in bonding to chlorhexidine-treated dentin. Dent Mater 2012;28:495-501.

44. Blackburn RS, Harvey A, Kettle LL, Manian AP, Payne JD, Russell SJ, et al. Sorption of chlorhexidine on cellulose: Mechanism of binding and molecular recognition. J Phys Chem B 2007;111:8775-84.

45. Kim J, Uchiyama T, Carrilho M, Agee KA, Mazzoni A, Breschi L, et al. Chlorhexidine binding to mineralized versus demineralized dentin powder. Dent Mater 2010;26:771-8. 